\title{
Genetic variation of natural antibodies in milk of Dutch Holstein-Friesian cows
}

\author{
T. C. W. Ploegaert, ${ }^{*}{ }^{1}$ S. Wijga, $†$ E. Tijhaar, ${ }^{*}$ J. J. van der Poel, $†$ T. J. G. M. Lam, $\ddagger$ H. F. J. Savelkoul, ${ }^{*}$ \\ H. K. Parmentier,§ and J. A. M. van Arendonk† \\ ${ }^{*}$ Cell Biology and Immunology Group, and \\ †Animal Breeding and Genomics Centre, Wageningen University, PO Box 338, $6700 \mathrm{AH}$ Wageningen, the Netherlands \\ fDutch Udder Health Center, PO Box 2030, 7420 AA Deventer, the Netherlands \\ §Adaptation Physiology Group, Wageningen University, PO Box 338, 6700 AH Wageningen, the Netherlands
}

\section{ABSTRACT}

Defense mechanisms of dairy cows against diseases partly rest on their naturally present disease resistance capacity. Natural antibodies (NAb) form a soluble part of the innate immune system, being defined as antibodies circulating in animals without prior intentional antigenic stimulation. Genetic selection on NAb titers in milk, therefore, might improve disease resistance. We estimated genetic parameters of NAb titers binding lipopolysaccharide, lipoteichoic acid (LTA), peptidoglycan, and keyhole limpet hemocyanin, and titers of the $\mathrm{NAb}$ isotypes IgG1, IgM, and IgA binding LTA in milk of Dutch Holstein-Friesian heifers. Natural antibody titers were measured in 1 milk sample from each of 1,939 Holstein-Friesian heifers and used for estimating genetic parameters of NAb titers. The data show that phenotypic variation exists among heifers in NAb titers binding lipopolysaccharide, LTA, peptidoglycan, and keyhole limpet hemocyanin, and the NAb isotypes IgG1, IgM, and IgA binding LTA in milk. High genetic correlations among $\mathrm{NAb}$ (ranging from 0.45 to 0.99 ) indicated a common genetic basis for the levels of different NAb in bovine milk. Intra-herd heritability estimates for NAb ranged from 0.10 to 0.53 . The results indicated that NAb levels have potential for genetic selection.

Key words: genetic variation, natural antibody, dairy cow

\section{INTRODUCTION}

Innate immunity plays an important role in preventing or combating infection. Knowledge of protection from intramammary infection or other infections of cattle by (components of) innate immunity is scarce. A potentially important humoral component of innate im-

\footnotetext{
Received March 15, 2010.

Accepted July 9, 2010

${ }^{1}$ Corresponding author: Tosca.Ploegaert@wur.nl
}

munity is formed by natural antibodies (NAb) (Baumgarth et al., 2005; Elluru et al., 2008), being defined as antibodies present in nonimmunized individuals (Van Knegsel et al., 2007). In mice and human, NAb are preferentially derived from $\mathrm{CD}^{+} \mathrm{B}$ (B1) cells (Casali and Notkins, 1989). Natural antibodies are characterized by a broad-specificity repertoire, usually with low binding affinity (Casali and Notkins, 1989). In mammals, NAb are mostly of the IgM isotype class, but IgG and IgA NAb have been described as well (Boes, 2000), and are thought to provide a barrier to infection, and subsequently act as an adjuvant of specific immunity (reviewed by Kohler et al., 2003).

Natural antibodies are present in bovine milk and blood plasma (Van Knegsel et al., 2007; T. Ploegaert, unpublished data). Furthermore, increasing titers of $\mathrm{NAb}$ were found in blood and milk of aging cattle (Srinivasan et al., 1999; Van Knegsel et al., 2007). This suggests that NAb are the cumulative result of antigenic stimulation, by continuous polyclonal stimulation by exogenous microbes, or self-antigens, or both (Tomer and Shoenfeld, 1988; Avrameas, 1991; reviewed by Kohler et al., 2003). A high proportion of NAb (reviewed by Kohler et al., 2003) binds pathogen-associated molecular patterns that represent antigens shared by classes of microbes and serve as targets for identification of microbes by the innate immune system. Important pathogen-associated molecular patterns are LPS present on gram-negative (entero)bacteria, such as Escherichia coli or Salmonella spp.; lipoteichoic acid (LTA) present on gram-positive bacteria, such as Staphylococcus aureus; or peptidoglycan (PGN) present on gram-negative and gram-positive bacteria. A relationship was suggested between NAb titers binding keyhole limpet hemocyanin (KLH) or LPS and body condition, energy balance, milk yield, and plasma cholesterol concentration in the peripartum period (Van Knegsel et al., 2007).

Earlier, we found that NAb titers are repeatable over time and show variation among cows (T. Ploegaert; unpublished data). Natural antibody titers in milk are 
thus an easily measured parameter of humoral innate immunity that might be involved in dairy cattle disease resistance. Natural antibodies binding specific pathogens or antigens have been proposed to enhance protection against subsequent infection (reviewed by Kohler et al., 2003). Genetic variation in total levels of bovine serum isotype immunoglobulins (IgG1, IgG2, IgM, and $\operatorname{IgA}$ ) have been published (Mallard et al., 1983). In poultry, heritability $\left(h^{2}\right)$ of total NAb was approximately 0.23 (Wijga et al., 2009). To our knowledge, information on $h^{2}$ of total NAb and their isotypes in dairy cattle, especially in milk, is scarce. Therefore, the first aim of this study was to estimate genetic parameters of total NAb titers binding LPS, LTA, PGN, and KLH in Dutch Holstein-Friesian heifers. Furthermore, because Staph. aureus is one of the important pathogens causing mastitis, the second aim was to estimate genetic parameters of antibody isotypes IgG1, IgM, and IgA in milk binding LTA from Staph. aureus.

\section{MATERIALS AND METHODS}

\section{Animals}

This study builds on samples collected in the Dutch Milk Genomics Initiative, a project that focuses on the genetic background of detailed milk composition. As part of this project, milk samples were collected from 1,953 first-parity cows in 398 commercial herds in the Netherlands during the first quarter of 2005 (Stoop et al., 2008). At least 5 cows per herd were present at the start of the experiment. Data collection was designed for estimating genetic parameters (many small families) and linkage analysis (some large families). The aim was to have 20 offspring from each of 50 young bulls and 200 offspring from each of 5 proven bulls. In total, 857 offspring from 50 young bulls and 909 offspring from 5 proven bulls were included. To obtain the minimum of 5 offspring per herd, 187 offspring from other proven bulls were included. Each cow was between 5 and $220 \mathrm{~d}$ in lactation at the start of the experiment. Cows were over $87.5 \%$ Holstein-Friesian. Pedigree and milk yield records of each of the 1,953 selected cows were provided by the cattle cooperative (CRV, Arnhem, the Netherlands). After data editing (cows with missing data were deleted), information on 1,939 milk samples remained, all of which were used in the analyses. Of those 1,939 milk samples, 1,450 had $<80,000$ somatic cells/mL.

\section{Milk Samples}

Morning milk samples from 1,953 Dutch HolsteinFriesian cows in their first lactation (cows were milked twice a day), located in 398 herds, were collected.
The samples were preserved with $0.03 \%$ (wt/wt) sodium azide, transported refrigerated, and stored frozen at $-40^{\circ} \mathrm{C}$ within $1 \mathrm{~d}$. Before testing the $\mathrm{NAb}$ titers, samples were aliquoted and stored at $-20^{\circ} \mathrm{C}$.

Somatic cell count was determined as part of the regular milk recording at the certified laboratory of the Milk Control Station (Qlip, Zutphen, the Netherlands) and supplied to us by CRV. Somatic cell score was calculated by transforming SCC as follows: SCS $=\ln (\mathrm{SCC} / 1,000)$. In an earlier study we found a high repeatability (0.71 to 0.91$)$ of NAb titers within cows over time (T. Ploegaert; unpublished data), indicating that it is sufficient to analyze a single milk sample of a cow. Repeatability was calculated from 10 repeated measurements over a time span of almost $3 \mathrm{wk}$ as the between-cow variance expressed as fraction of phenotypic variance.

\section{Total Natural Antibodies and Antibody Isotypes}

In milk samples, titers of total NAb binding Escherichia coli-derived LPS (L2880, serotype O55:B5), Staph. aureus-derived LTA [L2515, both from Sigma-Aldrich Inc. (St. Louis, MO)], Staph. aureus-derived PGN (BioChemika, Buchs, Switzerland), or Megathura crenulataderived KLH from MP Biomedicals (Solon, $\mathrm{OH}$ ) were determined. In addition, the isotypes IgG1, IgM, and IgA of antibodies binding LTA were measured. Titers of NAb were determined using an indirect ELISA procedure, essentially as described by Van Knegsel et al. (2007). In short, plates were coated with $100 \mu \mathrm{L} /$ well of $1 \mu \mathrm{g}$ of KLH, $4 \mu \mathrm{g}$ of LPS, $5 \mu \mathrm{g}$ of LTA, or $2 \mu \mathrm{g}$ of PGN per $\mathrm{mL}$ of carbonate buffer $\left(10.6 \mathrm{~g} / \mathrm{L} \mathrm{Na}_{2} \mathrm{CO}_{3}, \mathrm{pH} 9.6\right)$. After washing, plates were blocked with $100 \mu \mathrm{L} /$ well of $2.5 \%$ rabbit serum in PBS with $0.05 \%$ Tween 20 for at least $30 \mathrm{~min}$ at room temperature $\left(21^{\circ} \mathrm{C}\right)$. Four serial dilutions of samples (1:4) in PBS, $0.05 \%$ Tween20, and $2.5 \%$ rabbit serum were added. Dilutions started at 1:30 for analysis of total antibodies and at 1:4 for analysis of isotypes. On each plate, the same positive sample was included with 8 serial dilutions (1:2) in duplicate. Plates were incubated for $1 \mathrm{~h}$ at room temperature $\left(21^{\circ} \mathrm{C}\right)$. Binding of total antibodies to LPS, LTA, PGN, or KLH was detected using $100 \mu \mathrm{L} /$ well of 1:15,000 diluted rabbit anti-bovine antibody $(\mathrm{H}+\mathrm{L})$ coupled to peroxidase (Sigma-Aldrich Inc.). Binding of isotype antibodies to LTA was detected using 1:16,000 diluted sheep antibovine IgG1 (Serotec, Düsseldorf, Germany), 1:16,000 diluted sheep anti-bovine IgM (Serotec), or 1:8,000 diluted sheep anti-bovine IgA (Serotec), all coupled to horseradish peroxidase. After washing, $100 \mu \mathrm{L} /$ well of tetramethylbenzidine $(71.7 \mu \mathrm{g} / \mathrm{mL})$ and $0.05 \% \quad \mathrm{H}_{2} \mathrm{O}_{2}$ were added to the wells and incubated for $10 \mathrm{~min}$ at room temperature $\left(21^{\circ} \mathrm{C}\right)$. The reaction was stopped 
with $50 \mu \mathrm{L} /$ well of $2.5 \mathrm{~N}$ of $\mathrm{H}_{2} \mathrm{SO}_{4}$. Extinctions were measured with a Multiskan spectrophotometer (Flow, Irvine, UK) at a wavelength of $450 \mathrm{~nm}$. Levels were calculated as titers, and titers were expressed as $\log _{2}$ values of the dilutions that gave an extinction closest to $50 \%$ of Emax, where Emax represents the highest mean extinction of a standard positive milk sample present in duplicate on every microtiter plate (Ploegaert et al., 2007; Van Knegsel et al., 2007; Star et al., 2009).

\section{Statistical Analysis}

Variance components for genetic and herd effects were estimated with an animal model using ASReml (Gilmour et al., 2006). The animal model was the same as that used in the other studies on detailed milk composition on the same data set (Stoop et al., 2007, 2008; Schopen et al., 2008):

$$
\begin{aligned}
& y_{i j k l m n}= \mu+b_{1} \times \operatorname{dim}_{i}+b_{2} \times e^{-0.05 \times d i m}+b_{3} \times a f c_{j} \\
&+b_{4} \times \text { afc }_{j}^{2}+\text { season }_{k}+\text { scode }_{l}+\text { herd } \\
& m
\end{aligned}
$$

where $y_{i j k l m n}=$ dependent variable corresponding to milk NAb titer of cow $n$ with a sire code $l$, age of first calving $j$ during season $k$ and at DIM (time between calving and date of sample) $i ; \mu=$ general mean; $\operatorname{dim}_{i}=$ DIM, modeled with a Wilmink curve (Wilmink, 1987) with regression coefficients $b_{1}$ and $b_{2} ; a f c_{j}=$ covariate describing the effect of age at first calving; $b_{3}$ and $b_{4}$ were regression coefficients for $a f c$ and $a f c^{2}$; season $_{k}=$ 3 classes for season of calving: summer (June-August 2004), autumn (September-November 2004), and winter (December 2004-February 2005); scode $_{l}=$ fixed effect accounting for differences between groups of proven bull daughters and young bull daughters; $h e r d_{m}$ $=$ random effect of herd $m ; A_{n}=$ random additive genetic effect of animal $n$; and $E_{i j k l m n}=$ random residual effect. Relationships between animals were taken into account. The pedigree included 26,300 animals (Stoop et al., 2007). Univariate analyses were used to estimate the intra-herd heritability, which was defined as

$$
h^{2}=\frac{\sigma_{A}^{2}}{\sigma_{A}^{2}+\sigma_{E}^{2}},
$$

where $\sigma_{A}^{2}$ is the additive genetic variance and $\sigma_{E}^{2}$ is the residual variance. The intra-herd heritability expresses the proportion of phenotypic variance that can be explained by additive genetic variation between animals within herds.
Univariate analyses were also used to estimate the across-herd heritability $\left(h_{a c}^{2}\right)$ that was defined as

$$
h_{a c}^{2}=\frac{\sigma_{A}^{2}}{\sigma_{\text {herd }}^{2}+\sigma_{A}^{2}+\sigma_{E}^{2}},
$$

where $\sigma_{\text {herd }}^{2}$ is the between-herd variance.

The proportion of the total phenotypic variance due to variation between herds $\left(h_{\text {herd }}\right)$ was calculated as

$$
h_{\text {herd }}=\frac{\sigma_{\text {herd }}^{2}}{\sigma_{\text {herd }}^{2}+\sigma_{A}^{2}+\sigma_{E}^{2}} .
$$

Genetic correlation $\left(r_{g}\right)$ between 2 traits (A1 and A2) was estimated from bivariate analyses using model [1] as

$$
r_{g}=\frac{\sigma_{A 1, A 2}^{2}}{\sqrt{\left(\sigma_{A 1}^{2} \times \sigma_{A 2}^{2}\right)}},
$$

where $\sigma_{A 1}^{2}$ is the additive genetic variance for NAb titer $\mathrm{A} 1, \sigma_{A 2}^{2}$ is the additive genetic variance for NAb titer $\mathrm{A} 2$, and $\sigma_{A 1, A 2}^{2}$ is the additive genetic covariance between NAb titers A1 and A2. Correlations were calculated for the different total NAb titers and for the $3 \mathrm{NAb}$ isotypes IgG1, IgM, and IgA binding LTA. Results of univariate analyses were used as starting values for variance structure in the bivariate analyses.

\section{RESULTS}

\section{Natural Antibody Titers}

Titers of NAb binding LPS, LTA, PGN, and KLH as well as titers of the isotypes IgG1, IgM, and IgA binding LTA in milk were determined. Table 1 shows the mean and standard deviation of titers of NAb binding LPS, LTA, PGN, KLH, and isotypes IgG1, IgM, and IgA binding LTA in milk. For the total antibodies, NAb titers binding LPS were, on average, lowest (3.22) and NAb titers binding PGN were highest (5.68). For the antibody isotypes, the IgA titers binding LTA were, on average, lowest (2.87), whereas IgM titers were, on average, highest (4.26). Substantial differences in titers between animals were found: the coefficient of variation ranged from $19 \%$ for $\mathrm{NAb}$ binding $\mathrm{KLH}$ to $41 \%$ for isotypes IgG1 and IgA binding LTA. 
Table 1. Mean titer, standard deviation, and coefficient of variation of total natural antibody titers ${ }^{1}$ and natural antibody isotype (IgG1, IgM, IgA) titers binding lipoteichoic acid (LTA) measured in milk samples of 1,939 heifers

\begin{tabular}{lccc}
\hline Antibody & Mean & SD & CV $(\%)$ \\
\hline KLH & 3.88 & 0.77 & 20 \\
LPS & 3.22 & 0.97 & 30 \\
LTA & 3.44 & 0.90 & 26 \\
PGN & 5.68 & 1.06 & 19 \\
LTA-IgG1 & 3.40 & 1.39 & 41 \\
LTA-IgM & 4.26 & 0.89 & 21 \\
LTA-IgA & 2.87 & 1.18 & 41 \\
\hline
\end{tabular}

${ }^{1} \mathrm{KLH}=$ keyhole limpet hemocyanin; LTA = lipoteichoic acid; PGN $=$ peptidoglycan.

\section{Phenotypic Variance, Heritability, and Herd Effect of Natural Antibody Titers}

Table 2 shows estimates of intra-herd heritabilities, across-herd heritabilities, and herd effects for total antibody titers binding KLH, LTA, LPS, and PGN, and titers of antibody isotypes of IgG1, IgA, and IgM binding LTA in milk of all clinically healthy cows. Lowest intra-herd heritabilities were found for titers of IgG1 binding LTA (0.10) and highest intra-herd heritabilities were found for total NAb titers binding KLH (0.42), titers of IgM binding LTA (0.47), and IgA binding LTA (0.53). Across-herd heritabilities were also lowest for titers of IgG1 binding LTA and highest for total titers binding KLH and IgM and IgA titers binding LTA, but generally somewhat lower than intra-herd heritabilities. Herd effects explained between 11 and $29 \%$ of the phenotypic variance in the different traits (Table 2). The lowest contribution of herd effects was found for total NAb titers binding LPS (11\%), and the highest value was found for total NAb titers binding PGN (29\%).

Table 3 shows estimates of intra-herd heritabilities, across-herd heritabilities, and herd effects of total NAb titers binding KLH, LTA, LPS, and PGN, and NAb isotype titers of $\operatorname{Ig} \mathrm{G} 1, \operatorname{IgM}$, and $\operatorname{IgA}$ binding LTA in milk. This analysis included only cows that were considered clinically healthy and had SCC $<80,000$ cells $/ \mathrm{mL}$ at the time of milk sampling, because this cut-off value was earlier recognized to represent cows with healthy udders (Schepers et al., 1997). The lowest intra-herd heritability was found for NAb titers of IgG1 binding LTA (0.23) and the highest values for titers of IgM and IgA binding LTA (0.51). Across-herd heritabilities were also lowest for titers of IgG1 binding LTA and highest for IgM and IgA titers binding LTA, but generally somewhat lower than the intra-herd heritabilities. Herd effects explained 12 to $31 \%$ of the phenotypic variance found in the different traits (Table 3). The lowest value for herd effects was found for total NAb titers binding LTA and IgM binding LTA (12\%), and the highest level was found for total NAb titers binding PGN (31\%).

\section{Genetic and Phenotypic Correlations of Natural Antibody Titers}

Table 4 shows the genetic and phenotypic correlations between the total NAb titers binding LPS, LTA, PGN, and KLH. A high positive genetic correlation (0.99) was found between NAb titers binding LTA and LPS, and between NAb titers binding KLH and LTA $(0.85)$. The lowest genetic correlation $(0.45)$ was found between NAb titers binding PGN and KLH. As expected, phenotypic correlations were lower than genetic correlations. The phenotypic correlations ranged from 0.22 between NAb titers binding PGN and LPS to 0.50 between LTA and KLH.

Table 5 shows the genetic and phenotypic correlation between the $\mathrm{NAb}$ isotype titers IgG1, IgM, and IgA binding LTA. The genetic correlations between IgG1 and total NAb titers binding LTA (0.97) and between IgM and total NAb titers binding LTA (0.93) were highest, with low standard errors. The genetic correlation between IgG1 and IgM titers binding LTA was 0.80 and between IgG1 and IgA titers binding LTA 0.71. These estimated genetic correlations had high standard errors (0.19 to 0.21). Phenotypic correlations varied from 0.30 between IgG1 and IgA titers to 0.60 between total NAb and IgM titers binding LTA.

Table 2. Phenotypic variance $\left(\sigma_{P}^{2}\right)$, intra-herd heritability $\left(h^{2}\right)$, across-herd heritability $\left(h_{a c}^{2}\right)$, and herd effect $\left(h_{\text {herd }}\right)$ for total natural antibody titers binding keyhole limpet hemocyanin (KLH), lipoteichoic acid (LTA), LPS, and peptidoglycan (PGN), and natural antibody isotype titers binding LTA (LTA-IgG1, LTA-IgM, LTA$\operatorname{IgA})$

\begin{tabular}{lcccc}
\hline Antibody & $\sigma_{P}^{2}(\mathrm{SE})$ & $h^{2}(\mathrm{SE})$ & $h_{a c}^{2}(\mathrm{SE})$ & $h_{\text {herd }}(\mathrm{SE})$ \\
\hline KLH & $0.58(0.02)$ & $0.42(0.09)$ & $0.36(0.08)$ & $0.16(0.02)$ \\
LTA & $0.83(0.03)$ & $0.32(0.09)$ & $0.27(0.08)$ & $0.13(0.02)$ \\
LPS & $0.94(0.03)$ & $0.15(0.06)$ & $0.14(0.06)$ & $0.11(0.02)$ \\
PGN & $1.12(0.04)$ & $0.13(0.06)$ & $0.09(0.04)$ & $0.29(0.02)$ \\
LTA-IgG1 & $1.92(0.07)$ & $0.10(0.06)$ & $0.07(0.04)$ & $0.27(0.03)$ \\
LTA-IgM & $0.79(0.03)$ & $0.47(0.10)$ & $0.42(0.09)$ & $0.12(0.02)$ \\
LTA-IgA & $1.42(0.06)$ & $0.53(0.11)$ & $0.40(0.09)$ & $0.25(0.02)$ \\
\hline
\end{tabular}


Table 3. Phenotypic variance $\left(\sigma_{P}^{2}\right)$, intra-herd heritability $\left(h^{2}\right)$, across-herd heritability $\left(h_{a c}^{2}\right)$, and herd effect $\left(h_{\text {herd }}\right)$ for total natural antibody titers binding keyhole limpet hemocyanin (KLH), lipoteichoic acid (LTA), LPS, and peptidoglycan (PGN), and natural antibody isotype titers binding LTA (LTA-IgG1, LTA-IgM, LTAIgA) estimated from cows $(\mathrm{n}=1,450)$ that had a SCC $<80,000$ cells $/ \mathrm{mL}$ at the time of milk sampling

\begin{tabular}{lcccc}
\hline Antibody & $\sigma_{P}^{2}(\mathrm{SE})$ & $h^{2}(\mathrm{SE})$ & $h_{a c}^{2}(\mathrm{SE})$ & $h_{\text {herd }}(\mathrm{SE})$ \\
\hline KLH & $0.54(0.03)$ & $0.50(0.11)$ & $0.43(0.10)$ & $0.14(0.03)$ \\
LTA & $0.74(0.04)$ & $0.46(0.11)$ & $0.41(0.10)$ & $0.12(0.02)$ \\
LPS & $0.96(0.04)$ & $0.25(0.09)$ & $0.21(0.08)$ & $0.13(0.03)$ \\
PGN & $0.93(0.04)$ & $0.30(0.10)$ & $0.21(0.07)$ & $0.31(0.03)$ \\
LTA-IgG1 & $1.74(0.08)$ & $0.23(0.10)$ & $0.18(0.08)$ & $0.22(0.03)$ \\
LTA-IgM & $0.75(0.04)$ & $0.51(0.11)$ & $0.44(0.10)$ & $0.12(0.02)$ \\
LTA-IgA & $1.26(0.06)$ & $0.51(0.12)$ & $0.37(0.09)$ & $0.27(0.03)$ \\
\hline
\end{tabular}

\section{DISCUSSION}

Total NAb titers binding KLH, PGN, LTA, and LPS, and the NAb isotype titers IgG1, IgM, and IgA binding LTA in milk samples of 1,939 heifers, considered clinically healthy without known deliberate immunization, were measured. Titers of total NAb binding to all 4 antigens and NAb isotype titers binding LTA varied between these first-parity cows. Variation in NAb titers among cows was observed previously (Van Knegsel et al., 2007; T. Ploegaert, unpublished data), but cows were from different parities in these studies. Titers of NAb increased with parity (Van Knegsel et al., 2007) and consequently more variation would be expected when cows are from different parities.

Natural antibodies are potential immune parameters for natural disease resistance of dairy cows. Previously, we showed that NAb titers varied among cows and were repeatable within individual cows over time ( $\mathrm{T}$. Ploegaert, unpublished data). Results of the present study indicate that a substantial part of the variation between cows in (total) NAb titers binding LPS, LTA, PGN, and KLH is heritable (Table 2). Differences between herds explained between 11 and $29 \%$ of the phenotypic variance between cows. This knowledge is important for evaluation of the potential of genetic and nongenetic strategies for modulating NAb titers aiming at improving health of dairy cows. Levels of intra-herd heritability, for all cows considered clinically healthy, of total and isotype NAb titers in the present study ranged from 0.10 for IgG1 binding LTA to 0.53 for IgA binding LTA. In poultry, heritability ranged from 0.09 to 0.23 for NAb titers binding LPS and 0.03 to 0.42 for NAb titers binding LTA depending on line and age (Siwek et al., 2006) and 0.23 for NAb titers binding rabbit red blood cells (Wijga et al., 2009). Douch et al. (1995) estimated heritabilities for concentrations of total antibody (ranging from 0.25 to 0.37 ) and IgG1 (being around 0.19) binding 4 nematode species in serum from Romney lambs after natural exposure. Mallard et al. (1983) estimated a heritability of 0.08 to 0.85 for total IgM levels in serum of Canadian Holstein-Friesian dairy cows. Heritability estimates for specific antibody levels in serum after natural exposure to Mycobacterium avium ssp. paratuberculosis in Holstein cows ranged from 0.05 to 0.13 , depending on data set and model tested (Gonda et al., 2006; Hinger et al., 2008). Across-herd heritabilities of 0.36 for total NAb titers binding KLH, 0.42 for IgM titers binding LTA, and 0.40 for IgA titers binding LTA in the present study are among the highest reported for immune parameters in literature. The effect of udder health status on estimates of heritability of NAb titers was also studied. Estimates of intra-herd and across-herd heritability of total NAb titers and of isotype titers showed, in general, a slight increase when cows that were considered clinically healthy with SCC $>80,000$ cells $/ \mathrm{mL}$ were excluded from analyses (Table 3 ), compared with all cows that were considered clinically

Table 4. Genetic (above diagonal) and phenotypic (below diagonal) correlations between total natural antibody titers binding keyhole limpet hemocyanin (KLH), lipoteichoic acid (LTA), LPS, and peptidoglycan (PGN)

\begin{tabular}{|c|c|c|c|c|}
\hline & LPS & LTA & PGN & KLH \\
\hline LPS & - & $0.99(0.06)^{1}$ & $0.52(0.24)$ & $\mathrm{NE}^{2}$ \\
\hline LTA & $0.42(0.02)$ & - & $0.51(0.19)$ & $0.85(0.08)$ \\
\hline PGN & $0.22(0.02)$ & $0.43(0.02)$ & - & $0.45(0.20)$ \\
\hline KLH & $\mathrm{NE}$ & $0.50(0.02)$ & $0.26(0.03)$ & - \\
\hline
\end{tabular}

${ }^{1}$ Standard errors are in parentheses.

${ }^{2} \mathrm{NE}=$ estimates of parameters did not converge. 
Table 5. Genetic (above diagonal) and phenotypic (below diagonal) correlations between natural antibody isotype titers IgG1, IgM, and IgA binding lipoteichoic acid (LTA) and total natural antibody titers binding LTA

\begin{tabular}{lcccc}
\hline & LTA-IgG1 & LTA-IgM & LTA-IgA & LTA-Total \\
\hline LTA-IgG1 & - & $0.80(0.19)$ & $0.71(0.21)$ & $0.97(0.00)$ \\
LTA-IgM & $0.34(0.02)^{1}$ & - & $\mathrm{NE}^{2}$ & $0.93(0.05)$ \\
LTA-IgA & $0.30(0.03)$ & $\mathrm{NE}$ & - & $\mathrm{NE}$ \\
LTA-Total & $0.52(0.02)$ & $0.60(0.02)$ & $\mathrm{NE}$ & - \\
\hline
\end{tabular}

${ }^{1}$ Standard errors are in parentheses.

${ }^{2} \mathrm{NE}=$ estimates of parameters did not converge.

healthy (Table 2). Cows with SCC $<80,000$ cells $/ \mathrm{mL}$ are recognized as cows with a healthy udder (Schepers et al., 1997). These findings indicate that heritability of NAb is not negatively influenced by removal of cows with a potential subclinical intramammary infection, as indicated by the increased SCC values. Although possible sampling errors cannot be excluded totally, the results of the present study suggest that the estimates of NAb heritability are thus independent of the current intramammary infection status. In line with this observation, $\mathrm{NAb}$ might not reflect a response to current infection (Kohler et al., 2003).

Estimates of genetic correlations between titers of total NAb binding different antigens ranged from 0.45 to 0.99 (Table 4). These results suggest that a common genetic basis exists for the level of NAb binding these different antigens. Consequently, breeding for NAb titers may not require antibodies binding to specific pathogens or antigens, but might be based on a model antigen such as KLH (that cows have never encountered before) as a parameter of innate humoral immune competence.

Previous analysis showed that heritability estimates for milk production traits found in the Dutch Milk Genomics population (Stoop et al., 2007); that is, the population that was used in this study, were similar to estimates for these traits in literature (Hayes et al., 1984; Ikonen et al., 1999; Wood et al., 2003). The across-herd heritability estimate for SCS in the present study based on almost 2,000 heifer milk samples was 0.07 . This heritability estimate is well in the range of estimates for SCS reported (Da et al., 1992; Soyeurt et al., 2007; Arnould et al., 2009). These results suggest that our sample is representative of the Dutch dairy cow population.

Natural antibodies are usually IgM, but IgG and $\operatorname{IgA}$ NAb have been described as well (Boes, 2000). The presence of $\operatorname{IgM}, \operatorname{IgG}$, and $\operatorname{IgA} \mathrm{NAb}$ might reflect different conditions generating these NAb and resulting in different effector functions of NAb (Korhonen et al., 2000; reviewed by Kohler et al., 2003). The present study also shows IgG1, IgM, and IgA NAb titers bind- ing LTA in bovine milk. In these analyses (Table 2), estimates of the proportion of variance due to genetic factors (heritability) were substantially lower for IgG1 titers binding LTA (0.10) than for IgM titers binding LTA (0.47). In addition, the estimates of proportion of variation caused by environmental differences between herds (herd effect) were higher for IgG1 (0.27) than for $\operatorname{IgM}(0.12)$. This suggests that NAb of the IgG1 isotype might reflect earlier exposure to LTA. Earlier exposure could explain why the IgG1 titers are more affected by environmental than genetic factors of the cow, as reflected by the relatively high level of the herd effect and the relatively low heritability of IgG1 titers when compared with IgM titers (Table 2). On the other hand, IgM titers are naturally present (Casali and Notkins, 1989; Kohler et al., 2003), which could explain why the IgM titers, compared with IgG1 titers, were found to be more subject to genetic than environmental influences. High genetic correlations were estimated for the 3 isotypes binding LTA, which is in line with the dependency of IgG1 on the presence of IgM NAb, which do not increase due to infection (Kohler et al., 2003), but lower phenotypic correlations were estimated for the 3 isotypes binding LTA suggesting different (yet to be established) functions of the $3 \mathrm{NAb}$ isotypes in bovine milk. Earlier we found high repeatability of IgG1 binding LTA in cows that were considered clinically healthy (T. Ploegaert, unpublished data), suggesting that IgG1 NAb levels do not represent exposure per se.

Higher levels of NAb binding KLH were positively correlated with survival and health status in poultry (Star et al., 2007) and fish (Kachamakova et al., 2006). Whether higher NAb levels or NAb isotypes in bovine milk are indicative of the health status of dairy cows is currently being studied.

\section{CONCLUSIONS}

This study showed variation among first-parity cows in total NAb titers binding LPS, LTA, PGN, and KLH, and the isotype titers of IgG1, IgM, and IgA binding LTA in milk. High genetic correlations indicate a com- 
mon genetic basis for NAb titers in bovine milk. Heritability estimates demonstrate that total and isotype $\mathrm{NAb}$ levels have potential for genetic selection.

\section{ACKNOWLEDGMENTS}

This study is part of the five-year udder health program of the Dutch Udder Health Centre (Deventer, the Netherlands) and was financially supported by the Dutch Dairy Board (Zoetermeer, the Netherlands), CRV (Arnhem, the Netherlands), and the Dutch Agriculture and Horticulture Organization (LTO Noord, Zwolle, the Netherlands). Samples, pedigrees, and milk production, somatic cell count and mastitis data were kindly provided by the Milk Genomics Initiative. S. Wijga acknowledges financial contribution from the EU-project EADGENE.

\section{REFERENCES}

Arnould, V. M., H. Soyeurt, N. Gengler, F. G. Colinet, M. V. Georges, C. Bertozzi, D. Portetelle, and R. Renaville. 2009. Genetic analysis of lactoferrin content in bovine milk. J. Dairy Sci. 92:21512158.

Avrameas, S. 1991. Natural autoantibodies: From 'horror autotoxicus' to 'gnothi seauton'. Immunol. Today 12:154-159.

Baumgarth, N., J. W. Tung, and L. A. Herzenberg. 2005. Inherent specificities in natural antibodies: A key to immune defense against pathogen invasion. Springer Semin. Immunopathol. 26:347-362.

Boes, M. 2000. Role of natural and immune IgM antibodies in immune responses. Mol. Immunol. 37:1141-1149.

Casali, P., and A. L. Notkins. 1989. CD5+ B lymphocytes, polyreactive antibodies and the human B-cell repertoire. Immunol. Today 10:364-368.

Da, Y., M. Grossman, I. Misztal, and G. R. Wiggans. 1992. Estimation of genetic parameters for somatic cell score in Holsteins. J. Dairy Sci. $75: 2265-2271$.

Douch, P. G., R. S. Green, C. A. Morris, and S. M. Hickey. 1995. Genetic factors affecting antibody responses to four species of nematode parasite in Romney ewe lambs. Int. J. Parasitol. 25:823-828.

Elluru, S. R., J. Vani, S. Delignat, M. F. Bloch, S. Lacroix-Desmazes, M. D. Kazatchkine, S. V. Kaveri, and J. Bayry. 2008. Modulation of human dendritic cell maturation and function by natural IgG antibodies. Autoimmun. Rev. 7:487-490.

Gilmour, A. R., B. J. Gogel, B. R. Cullis, and R. Thompson. 2006. ASReml User Guide Release 2.0. VSN International Ltd., Hemel Hempstead, UK.

Gonda, M. G., Y. M. Chang, G. E. Shook, M. T. Collins, and B. W. Kirkpatrick. 2006. Genetic variation of Mycobacterium avium ssp. paratuberculosis infection in US Holsteins. J. Dairy Sci. 89:18041812.

Hayes, J. F., K. F. Ng-Kwai-Hang, and J. E. Moxley. 1984. Heritability of milk casein and genetic and phenotypic correlations with production traits. J. Dairy Sci. 67:841-846.

Hinger, M., H. Brandt, and G. Erhardt. 2008. Heritability estimates for antibody response to Mycobacterium avium subspecies paratuberculosis in German Holstein cattle. J. Dairy Sci. 91:3237-3244.

Ikonen, T., K. Ahlfors, R. Kempe, M. Ojala, and O. Ruottinen. 1999. Genetic parameters for the milk coagulation properties and prevalence of noncoagulating milk in Finnish dairy cows. J. Dairy Sci. $82: 205-214$.
Kachamakova, N. M., I. Irnazarow, H. K. Parmentier, H. F. Savelkoul, A. Pilarczyk, and G. F. Wiegertjes. 2006. Genetic differences in natural antibody levels in common carp (Cyprinus carpio L.). Fish Shellfish Immunol. 21:404-413.

Kohler, H., J. Bayry, A. Nicoletti, and S. V. Kaveri. 2003. Natural autoantibodies as tools to predict the outcome of immune response? Scand. J. Immunol. 58:285-289.

Korhonen, H., P. Marnila, and H. S. Gill. 2000. Milk immunoglobulins and complement factors. Br. J. Nutr. 84(Suppl. 1):S75-S80.

Mallard, B. A., E. B. Burnside, J. H. Burton, and B. N. Wilkie. 1983. Variation in serum immunoglobulins in Canadian Holstein-Friesians. J. Dairy Sci. 66:862-866.

Ploegaert, T. C., G. De Vries Reilingh, M. G. Nieuwland, A. Lammers, H. F. Savelkoul, and H. K. Parmentier. 2007. Intratracheally administered pathogen-associated molecular patterns affect antibody responses of poultry. Poult. Sci. 86:1667-1676.

Schepers, A. J., T. J. Lam, Y. H. Schukken, J. B. Wilmink, and W. J. Hanekamp. 1997. Estimation of variance components for somatic cell counts to determine thresholds for uninfected quarters. J. Dairy Sci. 80:1833-1840.

Schopen, G. C., H. Bovenhuis, M. H. Visker, and J. A. van Arendonk. 2008. Comparison of information content for microsatellites and SNPs in poultry and cattle. Anim. Genet. 39:451-453.

Siwek, M., B. Buitenhuis, S. Cornelissen, M. Nieuwland, E. F. Knol, R. Crooijmans, M. Groenen, H. Parmentier, and J. van der Poel. 2006. Detection of QTL for innate: non- specific antibody levels binding LPS and LTA in two independent populations of laying hens. Dev. Comp. Immunol. 30:659-666.

Soyeurt, H., F. G. Colinet, V. M. Arnould, P. Dardenne, C. Bertozzi, R. Renaville, D. Portetelle, and N. Gengler. 2007. Genetic variability of lactoferrin content estimated by mid-infrared spectrometry in bovine milk. J. Dairy Sci. 90:4443-4450.

Srinivasan, A., Y. Ni, and I. Tizard. 1999. Specificity and prevalence of natural bovine antimannan antibodies. Clin. Diagn. Lab. Immunol. 6:946-952.

Star, L., K. Frankena, B. Kemp, M. G. Nieuwland, and H. K. Parmentier. 2007. Natural humoral immune competence and survival in layers. Poult. Sci. 86:1090-1099.

Star, L., H. R. Juul-Madsen, E. Decuypere, M. G. Nieuwland, G. de Vries Reilingh, H. van den Brand, B. Kemp, and H. K. Parmentier. 2009. Effect of early life thermal conditioning and immune challenge on thermotolerance and humoral immune competence in adult laying hens. Poult. Sci. 88:2253-2261.

Stoop, W. M., H. Bovenhuis, and J. A. van Arendonk. 2007. Genetic parameters for milk urea nitrogen in relation to milk production traits. J. Dairy Sci. 90:1981-1986.

Stoop, W. M., J. A. van Arendonk, J. M. Heck, H. J. van Valenberg, and H. Bovenhuis. 2008. Genetic parameters for major milk fatty acids and milk production traits of Dutch Holstein-Friesians. J. Dairy Sci. 91:385-394

Tomer, Y., and Y. Shoenfeld. 1988. The significance of natural autoantibodies. Immunol. Invest. 17:389-424.

van Knegsel, A. T., G. de Vries Reilingh, S. Meulenberg, H. van den Brand, J. Dijkstra, B. Kemp, and H. K. Parmentier. 2007. Natural antibodies related to energy balance in early lactation dairy cows. J. Dairy Sci. 90:5490-5498.

Wijga, S., H. K. Parmentier, M. G. Nieuwland, and H. Bovenhuis. 2009. Genetic parameters for levels of natural antibodies in chicken lines divergently selected for specific antibody response. Poult. Sci. 88:1805-1810.

Wilmink, J. B. M. 1987. Adjustment of test-day milk, fat and protein yield for age, season and days-in-milk. Livest. Prod. Sci. $16: 335-348$.

Wood, G. M., P. J. Boettcher, J. Jamrozik, G. B. Jansen, and D. F. Kelton. 2003. Estimation of genetic parameters for concentrations of milk urea nitrogen. J. Dairy Sci. 86:2462-2469. 